\title{
Erratum to: The Maunder Minimum and the Sun as the Possible Source of Particles Creating Increased Abundance of the ${ }^{14} \mathrm{C}$ Carbon Isotope
}

\author{
Radosław Rek
}

Received: 6 January 2010 / Accepted: 6 January 2010 / Published online: 16 January 2010

(C) Springer Science+Business Media B.V. 2010

\section{Erratum to: Solar Phys}

DOI 10.1007/s11207-009-9432-8

In Section 3.3, paragraph 11 the sentence "Examination of observations described by Heweliusz show only few observations of the Sun during some years, as in 1662 (without catalogued Sun observations), 1663 (six days remarked as solar), 1664 (two solar observations), 1665 (one solar observation), 1666 (six observations) and others (Heweliusz, 1679)." should be replaced by: "Heweliusz in his catalogue of measurements of the Sun's altitude made with using a quadrant, described only six observations of the solar surface in the period 1662-1670, all of them in 1663 (Heweliusz, 1679)."

The author regrets these mistakes.

\section{References}

Heweliusz, J.: 1679, Machina Coelestis, Gdańsk.

The online version of the original article can be found under doi:10.1007/s11207-009-9432-8.

R. Rek $(\bowtie)$

Polish Astronomical Society, Bartycka 18 str, 00-716 Warsaw, Poland

e-mail: rek_radoslaw@tlen.pl 